\title{
Teaching Games Level Design Using the StarCraft II Editor
}

\author{
Dr Penelope Sweetser \\ School of Electrical Engineering and Computer Science \\ Queensland University of Technology, Australia \\ penny.sweetser@qut.edu.au
}

\begin{abstract}
Level design is often characterised as "where the rubber hits the road" in game development. It is a core area of games design, alongside design of game rules and narrative. However, there is a lack of literature dedicated to documenting teaching games design, let alone the more specialised topic of level design. Furthermore, there is a lack of formal frameworks for best practice in level design, as professional game developers often rely on intuition and previous experience. As a result, there is little for games design teachers to draw on when presented with the opportunity to teach a level design unit. In this paper, we discuss the design and implementation of a games level design unit in which students use the StarCraft II Galaxy Editor. We report on two cycles of an action research project, reflecting upon our experiences with respect to student feedback and peer review, and outlining our plans for improving the unit in years to come.
\end{abstract}

Keywords

games design, level design, higher education, unit design

\section{Introduction}

The use of games within education has been growing for many years (Charlier \& De Fraine, 2012). Games have been shown to be effective vehicles for teaching a variety of subjects, such as maths, languages, and science (Razak, Connolly \& Hainey, 2012). Games can be used to motivate computer science students to learn programming skills (Angotti, Hillyard, Panitz, Sung \& Marino, 2010; Eagle \& Barnes, 2009). Students can also gain valuable skills from learning to design games, such as problem solving, reasoning, and creative thinking (Cheng, 2009). However, as a degree in itself, games development is relatively new to higher education. As a result, there is little published on methods and approaches for teaching games design in higher education. The question therefore arises: how do we teach students to be effective game designers?

First, we should establish why it is important to teach students to design games. Apart from the growing importance of games in education, video games are becoming increasingly pervasive and influential in our society. The global video games market is expected to grow from US $\$ 52.5$ Billion in 2009 to US\$86.8 Billion in 2014 (Haukka \& Chorazy, 2011). However, the implications are not just financial. The majority of people are playing games regularly, with $92 \%$ of Australian households having a device that is used to play games and $57 \%$ of game players playing daily or every other day (Brand, 2012). The "typical" game player has also evolved over the last few years, with games reaching far and wide into society. The average Australian game player is now 32 years old, $43 \%$ of Australians aged 51 or over play games, and $47 \%$ of game players are female (Brand, 2012). Consequently, the design of video games is now playing an influential role in our everyday lives.

The majority of published work on teaching games development focuses on capstone projects (Bidarra, Boers, Dobbe \& Huijser, 2008; Linhoff \& Settle, 2009; Schaefer \& Warren, 2004) or 
developing team skills (Brown, Lee \& Alejandre, 2009; Maxim, 2006; Settle, Linhoff \& Berthiaume, 2008). There is a lack of papers focused on teaching games design, let alone the more specialised area of games level design. Level design is often referred to in games development as "where the rubber hits the road." It is where the player is confronted with the rules and content of the game. It is also an area in which there is a lack of formal frameworks for best practice, with professional game developers drawing largely on intuition and previous experience (Hullet \& Whitehead, 2010). Consequently, when presented with the opportunity to teach a unit on games level design, there is little in the way of industry frameworks or previous academic materials to draw upon. In this paper, we discuss the design and implementation of a unit on games level design. We report on two cycles of an action research project (Norton, 2009) to critique and improve the unit, reflecting on our experiences with reference to student feedback and peer review. The first cycle was conducted in 2011 and the second in 2012.

\section{Games Level Design}

The Queensland University of Technology (QUT) offers a three-year Bachelor of Games and Interactive Entertainment (BGIE) degree. In the BGIE, there are three majors: game design, animation, and software technologies. The Games Level Design unit is available to students who have completed the first and second year games design units. As a result, the majority of students enrolled in Games Level Design are third year students of the games design major. The Games Level Design unit was first offered in 2011 and was subsequently offered in 2012. In both years, the class size was approximately 60 students.

\section{Level Design}

Before we detail the design of the unit, it is first necessary to clarify what we mean by levels and what is entailed in the design of levels. The definition of levels is quite broad and varies significantly depending on the type of game. In general, levels are distinct areas in a game, which can be separated by geography, narrative, or gameplay (Rouse, 2004). In narrative-driven games, levels are like chapters in a book, with each level having tension and release moments that create an emotional curve. From a gameplay perspective, the separation and order of levels has a substantial impact on the flow of the game, as players often play one level per play session and feel a sense of accomplishment after completing each level.

The role of the games level designer is varied and complex. The overall goal of a level is to provide an engaging gameplay experience (Rouse, 2004). However, what this means and how this is achieved varies significantly from game to game. Creating a level involves constructing the map or physical layout of the level; designing and implementing the narrative and objectives; placing objects, enemies, and characters; scripting events and character/enemy behaviour; integrating aesthetics (e.g., sounds, music, lighting); and providing opportunities for exploration, problem solving, and other gameplay. In the production of a game, all this must be done amidst incomplete game design and implementation, changing requirements, buggy tools, shifting deadlines, and budget cuts.

\section{Teaching Approach}

Developing game levels is a very hands-on, practical activity, which can be thought of as "applied games design". Accordingly, teaching games level design necessitates a practical approach. Our practical approach to teaching games level design was underpinned by interactive, participatory lectures; hands-on practical sessions using StarCraft II in the games laboratory; and project-based assessment that resulted in a complete, playable, and engaging game level. 


\section{Lectures}

The content of the unit was taught in seven two-hour lectures (see Table 1). We also offered an additional two lectures that covered potential pathways for the students upon graduating: getting a job, independent game development, and games research. Due to the lecturer having substantial games industry experience, the lectures included numerous industry examples. The students were also encouraged to volunteer examples from their own game playing experiences, which contributed significantly to shaping the classes. The material covered in lectures included all facets of games level design, including gameplay, environments, storytelling, pacing, training, artificial intelligence $(\mathrm{AI})$, and getting feedback on levels via playtesting.

Table 1: Games Level Design lectures

\begin{tabular}{|c|c|}
\hline Lecture & Content \\
\hline 1. Introduction & $\begin{array}{l}\text { Introduction to the unit and games level design. } \\
\text { Basics of level design, good level design, and the } \\
\text { level design process. }\end{array}$ \\
\hline 2. Level Gameplay & $\begin{array}{l}\text { Gameplay, formal elements, world building, rules, } \\
\text { content, interactive worlds, and puzzles. }\end{array}$ \\
\hline 3. Level Environments & $\begin{array}{l}\text { Camera; visual information, design, style, and } \\
\text { theme; and game audio. }\end{array}$ \\
\hline 4. Storytelling in Levels & $\begin{array}{l}\text { Premise, characters, story, conflict, dramatic arc, } \\
\text { storytelling contexts, the player's story, level story } \\
\text { outline, narrative elements, and emergent narrative. }\end{array}$ \\
\hline 5. Level Pacing \& Training & $\begin{array}{l}\text { Play; training areas, approaches, and methods; } \\
\text { challenge, difficulty, dynamic difficulty adjustment; } \\
\text { pacing; and difficulty versus pacing. }\end{array}$ \\
\hline 6. Level Artificial Intelligence (AI) & $\begin{array}{l}\text { Game Al basics, goals of game } \mathrm{Al} \text {, and } \mathrm{Al} \text { by game } \\
\text { genre. Al in game levels: goals, motivations, key } \\
\text { concepts, scripted events, and emergent } \\
\text { characters. }\end{array}$ \\
\hline 7. User Testing Levels & $\begin{array}{l}\text { Playtesting: testers, script, methods, and phases. } \\
\text { User testing case studies and user testing plan. }\end{array}$ \\
\hline
\end{tabular}

\section{Practical sessions}

Twelve two-hour practical sessions were available to students (see Table 2). During practical classes, students engaged in hands-on tutorials using the StarCraft II Galaxy Editor, worked in groups on their levels, or participated in assessment items. The first two practical classes were dedicated to the students familiarising themselves with StarCraft II, as well as getting a feel for the types of levels that could be created using the editor. The next three classes introduced the students to using the editor by completing focused tutorials, deconstructing existing levels, and beginning prototyping of their own designs. The remainder of the practical classes allowed the students to meet in their groups and work on their levels with tutor support. 
Table 2: Games Level Design practical classes

\begin{tabular}{ll}
\hline Practical & Exercise \\
\hline 1: Play StarCraft II & $\begin{array}{l}\text { Play and analyse StarCraft II campaign and/or } \\
\text { Custom maps. }\end{array}$ \\
$\begin{array}{l}\text { 2. Play StarCraft II } \\
\text { 3. StarCraft II editor tutorials }\end{array}$ & $\begin{array}{l}\text { Complete tutorials for using the StarCraft II Galaxy } \\
\text { Editor. }\end{array}$ \\
4. Reverse engineering & $\begin{array}{l}\text { Work in groups to reverse engineer existing } \\
\text { StarCraft II levels. }\end{array}$ \\
5. Prototype proposals & $\begin{array}{l}\text { Prototype student proposal concepts in the } \\
\text { 6. Design document }\end{array}$ \\
7. Playtesting & Work on design document and/or levels in groups. \\
8-9. Level construction & Design and implement a level playtesting script. \\
10. Presentations & Work on levels in groups. \\
11. Level construction & Group presentations for assessment 2A. \\
12. Peer assessment & Work on levels in groups. \\
\hline
\end{tabular}

\begin{abstract}
Assessment
The assessment for the unit was comprised of five items (see Table 3), distributed throughout the semester, and culminating in the completion of a final, playable, level. Each piece of assessment was designed to step the students through the process necessary to help them arrive at their final product. The students worked in groups to develop their final level, which received a group mark. However, the majority of their work was assessed on an individual basis. The first two assessment items were entirely individual efforts. The first item (A1) involved the analysis of three community-created StarCraft II levels and the second item (A2) required each student to propose two levels that could be constructed for the group project.
\end{abstract}

Students were subsequently organised into groups of four, for which students could: a) choose their own groups, or b) request to be assigned to a group. Once in their groups, students needed to review the eight individual level proposals (from A2) and decide on a proposal to construct as their final level. Students were able to choose one of the eight proposals, a combined/modified proposal, or a new proposal. The students were required to adopt specific roles in the group (see Table 4), in order to try and manage the complexities that are often entailed with group assessment (Settle, Linhoff \& Berthiaume, 2008), as well as to more closely emulate a professional games design team. The purpose of the group roles was for each student to take the lead on their designated areas of the level design. However, it was still left to the students to ensure equitable division of workload, as the amount of work involved in each of these roles would vary depending on the individual level being developed. Each student was required to write a section of the level design document (A3) and to present a portion of the progress presentation (A4), corresponding to his or her assigned group role. 
Table 3: Games Level Design assessment

\begin{tabular}{llll}
\hline \multicolumn{1}{c}{ Assessment Item } & \multicolumn{1}{c}{ Mode } & Weight & \multicolumn{1}{c}{ Content } \\
\hline A1 $\begin{array}{l}\text { Level Design } \\
\text { Analysis }\end{array}$ & Individual & $15 \%$ & $\begin{array}{l}\text { Analyse three StarCraft II community } \\
\text { levels, with respect to game design } \\
\text { elements and innovation. }\end{array}$ \\
A2 $\begin{array}{l}\text { Level Design } \\
\text { Proposal }\end{array}$ & Individual & $15 \%$ & $\begin{array}{l}\text { Propose two potential levels to develop } \\
\text { in the group project. }\end{array}$ \\
A3 $\begin{array}{l}\text { Level Design } \\
\text { Document }\end{array}$ & $\begin{array}{l}\text { Group, } \\
\text { assessed } \\
\text { individually }\end{array}$ & $20 \%$ & $\begin{array}{l}\text { Full design document for the selected } \\
\text { level to be constructed in groups. }\end{array}$ \\
A4 $\begin{array}{l}\text { Progress } \\
\text { Presentation }\end{array}$ & $\begin{array}{l}\text { assessed } \\
\text { individually } \\
\text { Group, peer } \\
\text { assessed }\end{array}$ & $20 \%$ & $\begin{array}{l}\text { Reflective presentation on progress on } \\
\text { the group levels. }\end{array}$ \\
A5 & $30 \%$ & $\begin{array}{l}\text { Submission of the final levels, assessed } \\
\text { vinal Level peer playtesting and evaluation. }\end{array}$ \\
\hline
\end{tabular}

The final level (A5) was the only assessment item for which the students were assigned a group mark. In the final practical session of the semester, each student was required to play and grade two other levels. As a result, eight students graded each level. In order to grade a level, students played the level for up to 45 minutes and marked the level against a criteria sheet. The criteria sheet included criteria for narrative; goals and objectives; environment; gameplay; pacing and training; and innovation. In order to award the final mark for each level, the unit coordinator reviewed all the grades and feedback provided by the students and determined a moderated grade.

Table 4: Group roles

\begin{tabular}{ll}
\hline \multicolumn{1}{c}{ Role } & \multicolumn{1}{c}{ Responsibilities } \\
\hline Narrative \& Goals & Story, characters, goals, and objectives. \\
Map \& Level Flow & Layout, progression, and placement of objects/Al. \\
Gameplay \& Innovation & Gameplay elements, scripting, and innovation. \\
Playtesting \& Training & User testing plan, training, pacing, and difficulty. \\
\hline
\end{tabular}

\section{StarCraft II Galaxy Editor}

The assessment and practicals for the Games Level Design unit are based in the StarCraft II Galaxy Editor (see Figure 1). StarCraft II is a real-time strategy game, developed by Blizzard and released in 2010. The StarCraft II Galaxy Editor was selected as the development tool for this unit to enable the students to focus on level design. StarCraft II is a complete and highly polished product that includes an editor that is designed for end users, as opposed to game developers. There is a large community dedicated to making custom maps and campaigns for StarCraft II and, as a result, there is a wealth of examples, tutorials, and resources available to the students. Simultaneously, the Galaxy Editor is also a very flexible and powerful tool. The students are not limited to only creating real-time strategy game maps. Rather, they are able to extensively modify most aspects of the game, through terrain building, object editing, and scripting, to create a very diverse set of game experiences. Blizzard also generously provided each of our students with an educational license to use StarCraft II for free for the semester. 


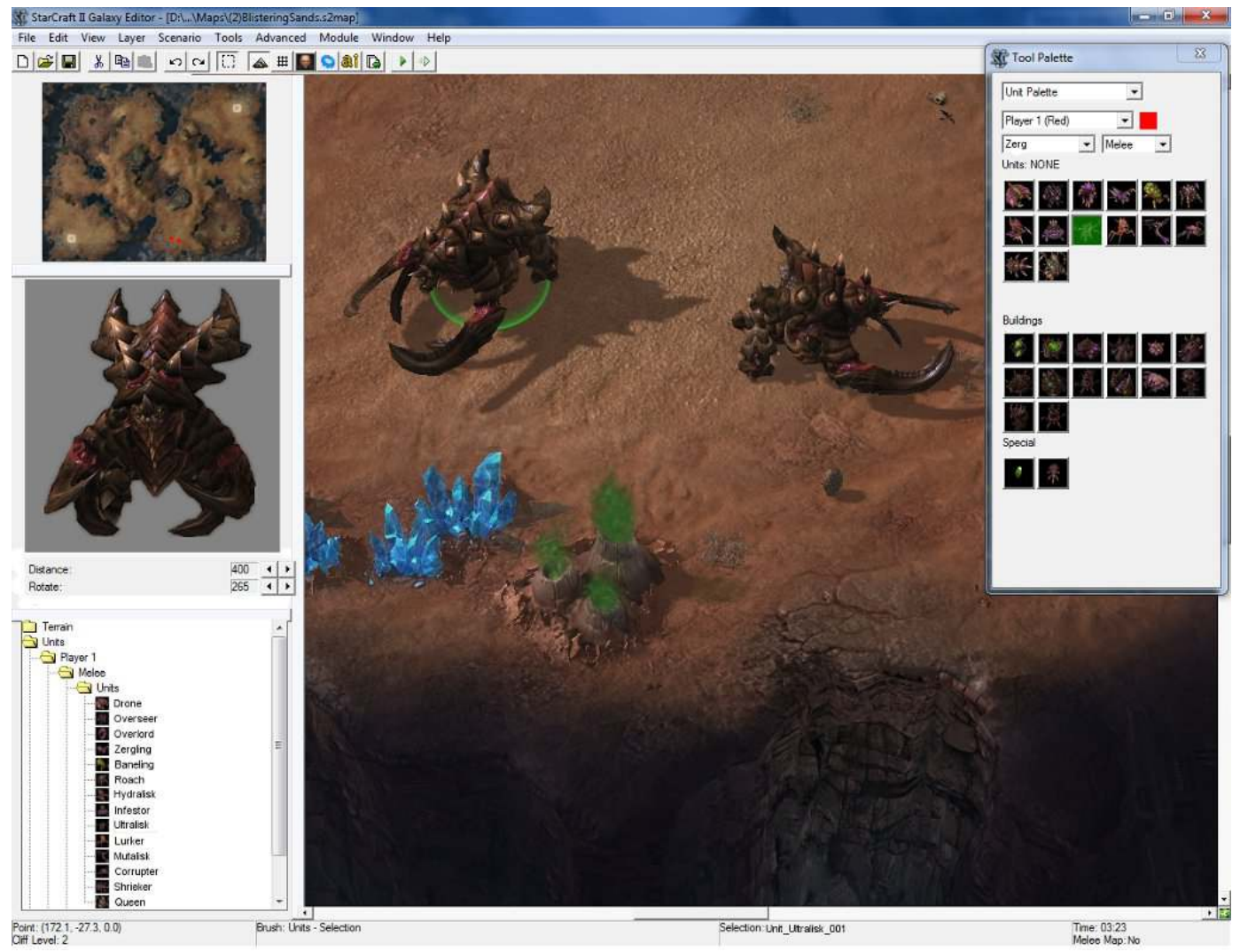

Figure 1: StarCraft II Galaxy Editor

\section{Student Projects}

In 2011, there were 14 final student projects in total, which included arcade, role-playing, racing, action, strategy, and simulation games. The students were instructed to create an innovative game level and to avoid developing a level that would fit comfortably within the existing StarCraft II campaign. Groups were to look at the tools and resources at hand and create an innovative and creative product. Each and every group demonstrated that they were capable of meeting this challenge.

In 2011, we were fortunate to have four of our student projects covered in a prominent Australian PC gaming magazine, PC Powerplay (Hull, 2011). The four games covered by the magazine were Silk Road, Eternal Templar, Space Cannonball Run II, and Starvest (see Figure 2). Silk Road is a space trading simulation game, Eternal Templar is a board-game inspired strategy game, Space Cannonball Run II is a combat racing game, and Starvest is an action role-playing game. The variation in these levels demonstrates the innovation displayed by the students, as well as the versatility and flexibility of the StarCraft II Galaxy Editor. 


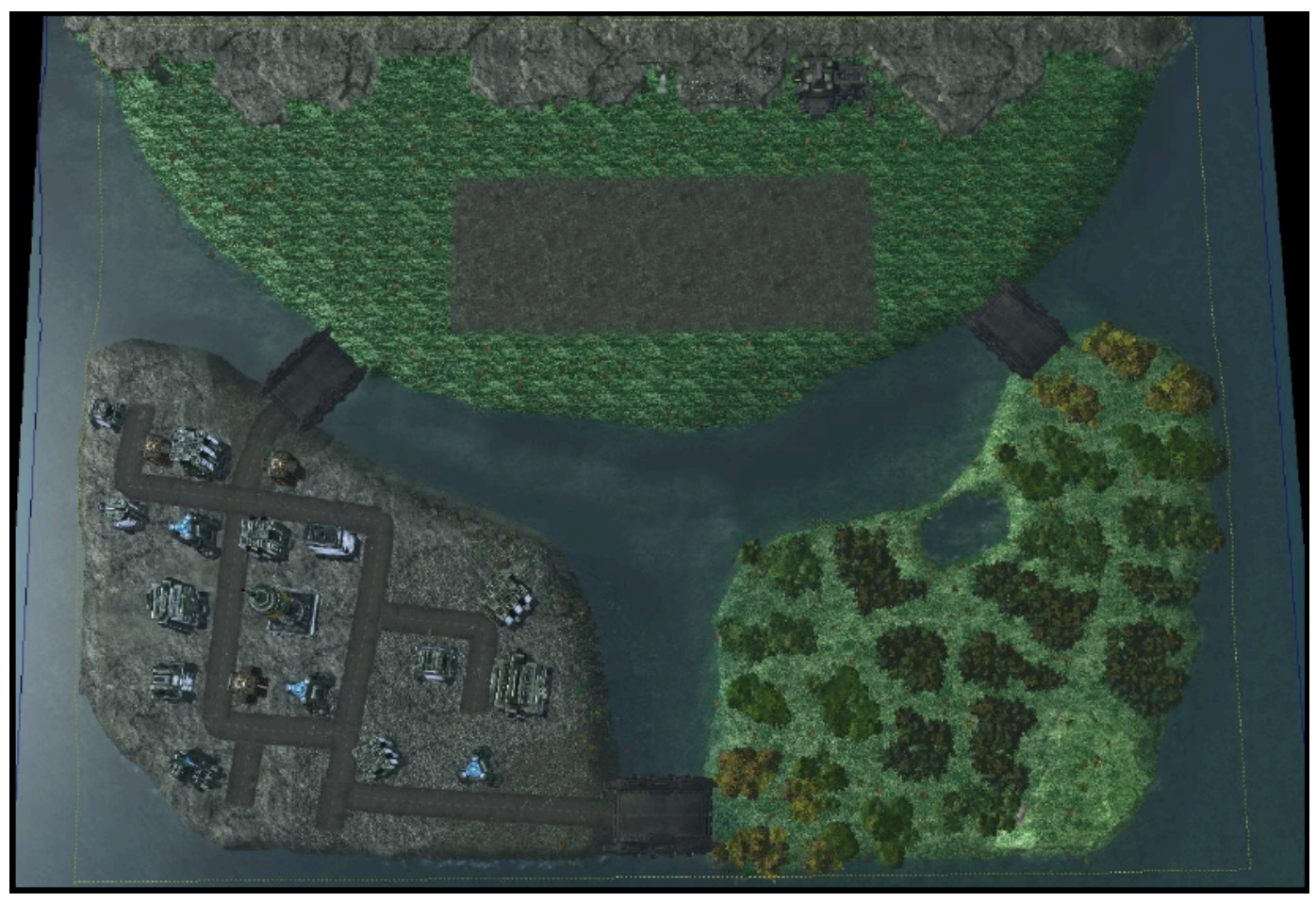

Figure 2: Starvest, an example level created by students using the StarCraft II editor

\section{Student Feedback}

In 2011, the students were asked to provide feedback on the unit twice during the semester. The first round of student feedback was collected midway through the semester, via an in-class online survey. The second round of student feedback was collected at the end of the semester, via the university's formal feedback mechanism, which is also administered via online survey.

\section{Mid-Semester Feedback}

During practical classes in week seven (out of 13) of semester, students were asked to participate in the mid-semester survey. The students were asked to respond to three questions:

- What have been the best learning experiences in games level design so far?

- $\quad$ Is there anything that you felt was missing or that you would like more time/support/information for?

- What would you recommend changing or adding to improve the unit in future?

\section{Best Learning Experiences}

There were 23 responses to the question relating to the students' best learning experiences so far in the unit. The responses most frequently related to the lectures $(\mathrm{N}=8)$, as well as to the practicals and use of the StarCraft II editor $(\mathrm{N}=8)$. Students responded that the lectures were interesting, well structured, useful, informative, involved open discussion, and that plenty of industry examples were provided. Students appreciated the hands-on practical classes and learning to use the StarCraft II editor. Students also enjoyed learning about level design in general $(\mathrm{N}=5)$, and found the assessment to be practical and well structured $(\mathrm{N}=2)$. 


\section{Lacking Support or Information}

There were 20 responses to the question relating to areas where the students felt they required additional support or information. The students' responses most frequently related to the practical classes $(N=10)$, followed by the lectures $(N=7)$, and the assessment $(N=3)$. Students' concerns with the practical classes related to wanting more direct instruction and technical support for using the StarCraft II editor and a clearer link between the lecture content and practical class exercises. For the lectures, the students wanted additional examples of good and bad level design, as well as audio recordings of the lectures to be made available. Finally, the students felt that they were spending too much time on written pieces of assessment and would have preferred to dedicate this time to working on their levels.

\section{Future Improvements}

There were 25 responses to the question relating to suggested future improvements and changes to the unit. The students' responses most frequently related to the assessment $(N=8)$ and lectures $(\mathrm{N}=8)$, followed by the use of StarCraft II $(N=4)$ and the practical classes $(N=5)$. In regards to the assessment, students suggested having fewer assessment items each with a higher weighting, with a particular view to removing some of the written assessment. For the lectures, students suggested more level-design specific content and less general game design content, as well as more examples and more use of videos. For the practical classes, students suggested more direct instruction, more technical support in using the editor, and more structured classes. Some students felt that they would have preferred to use a different tool to create their levels, rather than the StarCraft II editor. Although, it was suggested that any replacement tool would need to be as easy to use, include as many prebuilt assets, and have the same flexibility as StarCraft II.

\section{End of Semester Feedback}

At the end of each semester, QUT collects formal feedback from students on their units, courses, and teachers. For Games Level Design, students were asked to respond to two questions:

- What were the best aspects of this unit and why?

- What aspects of the unit are most in need of improvement and why?

\section{Best Aspects of the Unit}

There were 18 responses to the question relating to the best aspects of the unit. The students' responses most frequently related to the lectures $(N=6)$ and the use of StarCraft II $(N=6)$, followed by the unit overall $(N=4)$ and the assessment $(N=2)$. Students found the lectures to be informative, relevant, enjoyable, and grounded in industry practice. The students responded that using the StarCraft II editor simplified creating levels and allowed rapid development of prototypes and gameplay. They reported using a modern game as learning material to be "refreshing", appreciated being exposed to new technologies, and found it to be challenging but rewarding. The students reported that the unit overall was fun, relevant to their future careers, had a reasonable workload, and assisted them in understanding the fundamentals of good game design.

\section{Aspects for Improvement}

There were 22 responses to the question relating to aspects of the unit that needed improvement. The students' responses most frequently related to the assessment $(N=9)$ and the practical classes $(N=7)$, followed by the use of the StarCraft II editor $(N=3)$ and the unit overall $(N=3)$. Students reported that there was too much assessment overall and too much written, theoretical assessment in particular. They suggested that the first two assessment items be reduced or removed, which would allow more time to be dedicated to developing their levels. Students responded that the practical classes felt detached from the lecture material. They also would have liked more 
technical support from tutors in practical classes and did not like that they had to teach themselves how to use the editor for the most part. Some students did not like being forced to use the StarCraft II editor and suggested using Epic's UDK or Valve's Source engine instead, or allowing students to choose which tool they would use. Finally, some students felt that the unit was too focused on what they considered general games design, as opposed to level design. These students had expected the unit to be more about level architecture or construction (i.e., the physical mapping of the levels), rather than all aspects of level design.

\section{Peer Review}

In 2012, the Games Level Design unit was lectured and coordinated by a different academic, as the author was on maternity leave. As a result, we had the unique opportunity to gain feedback and input from a fellow lecturer, also with substantial games industry experience. Before handing over the unit, both lecturers met and discussed the 2011 implementation of the unit and made a plan for revisions in 2012. Likewise, at the end of 2012, both lecturers met again and discussed the 2012 implementation of the unit and the outcomes of the changes made to the unit. In addition, at the end of 2012, the author met with a graduate student who had completed the unit in 2011 and then went on to tutor the unit in 2012, to gain feedback on the design and implementation of the unit. Unfortunately, there was no feedback collected from students in 2012, due to the university revising their student feedback collection mechanism and the author being on maternity leave. In this section, we discuss the changes made to the unit in 2012 and the feedback from the review sessions held with both the 2012 lecturer and tutor.

\section{Lecturer's Reflections}

Following the completion of the 2011 iteration of the unit, the outgoing lecturer reflected on her experiences with the unit, in light of the student feedback, and made several recommendations for revisions to the unit for the incoming lecturer for 2012. The key recommendations were to:

- Remove assessment item A1, keeping it only as an in-class practical exercise. The reason for this recommendation was that the students seemed to struggle with the amount of assessment, particularly written assessment, and, that, although this constituted an important practical exercise, it wasn't crucial to assess this item.

- Reduce assessment item A2 to require the students to propose only one level to develop, rather than two. Reasoning for this recommendation again included reducing the amount of written assessment. However, it also seemed more useful to allow the students to concentrate on developing one solid proposal, rather than dividing their attention between two, potentially less polished, ideas.

- Separate out the professional design document from the academic theoretical justification. After marking the students' proposals and design documents, it was apparent that requiring the students to incorporate theoretical justification into their design documents resulted in documents that did not resemble industry documents. However, as understanding and articulating the theory behind their decisions was central to the unit, it was still necessary for this material to be assessed. Consequently, it was recommended that students should be required to separate out these two components of their assessment.

- $\quad$ Replace assessment item A4 with a practical class participation mark. The progress presentation did not meet the goals of providing the students with an opportunity for reflection and to review their progress. The students required more immediate feedback on their progress, as well as more encouragement to meet their team members on a regular basis. Consequently, a participation mark was suggested to encourage students to attend and participate in practical classes, including engaging with their team. 


\section{Implementation}

The major changes implemented in 2012 were to the assessment for the unit. In response to student feedback and the lecturer's reflections, a few key changes were made. Assessment A1 (see Table 3) was removed and kept only as a practical class exercise. Also, assessment A2 was modified so that students only needed to propose one level concept, rather than two. Assessment A4 was also removed, as students had required earlier, ongoing, and more immediate feedback on their progress. In place of assessment items A1 and A4, a participation mark for the practical classes was introduced instead. Students could gain a maximum of $35 \%$ of their grade for the unit by participating in practical classes, which included completing set exercises, participating in discussions, and working effectively with their teams on their projects. Another key change to the assessment was that students were required to clearly separate out the theoretical justifications in their proposals and design documents by using text boxes. In this way, the design could be kept clean and emulate a professional document, but still include the necessary theoretical underpinnings required to demonstrate academic merit.

\section{Peer Review Sessions}

Two peer review sessions were conducted, one with the 2012 lecturer and one with the 2012 tutor. Both review sessions took the format of informal, open discussions. The reviewers were first asked for any general feedback on the unit, which was then followed by questions relating specifically to assessment, lectures, practical classes, and the use of StarCraft II. Both reviewers reported that the unit went well and that informal feedback from the students was positive.

\section{Peer Review One}

The majority of the feedback from the 2012 lecturer related to the assessment. He found that the overall workload of the unit was more reasonable, with the removal of the two assessment items and the addition of the participation mark. He reported that the participation mark was effective in getting the students to attend and engage in the practical classes. He found that the roles for the project and design document worked well and resulted in an equitable workload division between the team members. However, he suggested that, in future, students could submit their individual components of the design document separately (rather than as a single group document), to ensure that each student was accountable for timely submission of their own work. He also suggested that participation marks could be collected via an online system (e.g., with an iPad in class), rather than marking with paper and pen in each class. Similarly, the students could directly enter their peer review marks for the final level marking session into an online system, to avoid the substantial amount of work in entering and collating student marks. Finally, he suggested that it would be worthwhile identifying team issues earlier on and having a contingency plan of what to do with students that aren't contributing to their team projects, such as taking on a smaller, individual project.

In regards to the use of StarCraft II, the lecturer reported that he felt that it worked well as the tool for the unit. He identified that the students that kept within the bounds of what the editor was designed for (i.e., top-down or third-person strategy, role-playing, or action games), were able to develop the most polished levels. He found that the students could face difficulties if they tried to stray too far from the core gameplay of the editor, particularly if they had little programming experience. He cited that a couple of the teams had made real-time strategy games, but that they had been able to do so without making StarCraft II clones. They simply kept away from the core mining, construction, and production mechanics of StarCraft II.

\section{Peer Review Two}

The feedback received from the 2012 tutor had more of a focus on the practical classes, the team projects, and the StarCraft II editor. The tutor identified that due to constant updates made to the StarCraft II editor, the editor walkthroughs used in the practical classes became quickly out of 
date, with some not working at all. She reported that some of the students were reluctant to get their hands dirty with the editor, particularly students who lacked programming skills, so she had made it a point to show them something new with the editor each week. She suggested that, in future, a key component of the editor (e.g., pathing, triggers) could be demonstrated to the students at the start of each practical class.

The tutor reported that the assessment provided a good workload for the students. She identified that, in general, the students had trouble with the theory in the assignments and that both written assignments had lacked theoretical justifications from the students. In regards to the projects, she reported that some students spent a lot of time on the aesthetics of their levels, rather than on the functionality. These students had been reluctant to fine-tune, balance, and polish their levels in response to playtesting feedback, despite having achieved functional levels early in the semester. She also identified that many students had issues with scope for their levels, trying to achieve too much in the small amount of time available to complete their levels. Finally, she found that students tried to stick too closely to their assigned group roles, which resulted in uneven distribution of work.

In regards to StarCraft II, the tutor reported that she thought it was a good choice for the unit. She identified that the editor is simple, has everything that the students need, and its limitations impose useful restrictions on the student projects. At the outset of the unit, the students were able to play the levels created by the 2011 students, which allowed them to get a feel for what the editor is capable of and what they can hope to achieve in a semester of development. She reported that the levels created by the 2012 students were innovative, despite the requirement for innovation being relaxed from the previous year. Only two teams made real-time strategy game levels, which were different to StarCraft II levels due to rich narratives created by the students.

\section{Reflections and Future Revisions}

Based on student feedback in 2011, it seems that the Games Level Design unit made a good addition to the BGIE degree, in terms of further developing the students' practical game design skills and building on their knowledge of game design theory. However, in its first iteration in 2011, the unit had a number of issues that needed some attention, in order to ensure students were getting the most out of their experience in the unit. The key areas that were identified as needing improvement in 2011 were the assessment and the practical classes. The changes made in 2012 made some progress towards addressing the issues identified by students in these areas. In this section, we reflect on the student feedback, changes to date, and peer reviews of the unit to identify opportunities for future improvement to the unit. In addition, it is necessary to review the choice of StarCraft II as the development tool for the unit and decide whether to continue with it in future years or to explore other options.

\section{Assessment}

In 2011, student feedback and lecturer reflections indicated that there was too much assessment for the unit, particularly written assessment. In response to this feedback in 2012, we removed the first written assessment item, reduced the size of the second written assessment item, and removed the progress presentation. In lieu of these assessment items, we added a practical class participation mark to encourage students to attend practical classes and engage with both the practical exercises and their project teams. Peer review suggested that these changes resulted in a more manageable workload for the students and that engagement in the practical classes was improved.

The peer review sessions identified a few outstanding issues that still need attention for the next iteration of the unit. Potential future improvements to the unit include: 
- $\quad$ Requiring each team member to submit their component of the team design document;

- Collecting practical class participation marks and final level peer reviews electronically;

- Using participation marks to help identify team issues earlier in the semester and responding quickly to support students in managing these issues;

- Clarifying the importance of clearly communicating theoretical justifications for written assignments;

- $\quad$ Ensuring students leave adequate time for responding to playtesting feedback and that they understand the importance of polishing, balancing, and fine-tuning their levels;

- Guiding teams in determining a realistic scope for their levels and supporting teams in equitable division of workload.

\section{Practical sessions}

In 2011, students reported that the practical classes felt detached from the lecture material and that they wanted more direct instruction and technical support for using the StarCraft II editor. No formal changes were made to the practical classes in 2012. However, a notable improvement came from having a tutor who had completed the unit the year before and who could provide extensive technical support to the students in using the StarCraft II editor.

Based on student feedback and lecturer reflections from 2011 and the peer reviews from 2012, potential future improvements to the practical classes include:

- $\quad$ Review the practical classes to improve alignment with lecture material.

- Update practical class exercises to reflect the current (and changing) state of the StarCraft II editor.

- Include a short instructional session and practical exercises using the StarCraft II editor in each practical class.

\section{StarCraft II}

In 2011, feedback indicated that student opinion was divided on the use of the StarCraft II editor for the unit. Some students found StarCraft II to be simple, powerful, and exactly what they needed to create their levels. Conversely, other students indicated that they would have preferred to use another editor (e.g., Epic's UDK or Valve's Source engine) or have been allowed to choose their own editor. This feedback raised the question of whether another tool should be selected for the unit or whether students should be permitted to choose their own tool.

The peer review feedback following the 2012 iteration of the unit supported the continued use of StarCraft II as the tool for the unit. The teaching staff reported that it was simple, had everything the students required, and also limited what they were able to do, which helped in constraining their projects. In addition, the accumulation of levels created by previous teams of students in 2011, and now 2012, further supports future students by providing examples and benchmarks of what can be achieved in the unit. The peer reviews also confirmed the author's hesitations in allowing students to select their own development tool, in that limited technical support could be provided to the students across multiple tools. The issues with using the other suggested tools were 
also confirmed by the peer reviews, which were that the students would be overly focused on level architecture, rather than level design as a whole. Consequently, the continued use of StarCraft II for the unit seems to be the best choice at this stage.

\section{Conclusions}

The goals of this paper were to discuss the design and implementation of a games level design unit, along with our reflections on the first two iterations of the unit, and plans for future improvements. Thoughts and experiences of designing and running a games level design unit have been shared in the hope that this approach and lessons learned will inform other educators in the same endeavour. In addition to the detailed analysis of this unit, reflections on some important general issues have been provided, including achieving the difficult balance between academic theory and industry practice; providing students with sufficient scaffolding for learning while not over-assessing; the benefits of using contemporary industry examples and tools; designing for fair group assessment and supporting teams in game development projects; and the importance of providing technical support to students for complex tools. Through this paper, some progress has been made in providing guidance to educators in developing games design units and also in answering the broader question of how students can be encouraged to be effective game designers.

\section{References}

Angotti, R., Hillyard, C., Panitz, M., Sung, K., \& Marino, K. (2010). Game-themed instructional modules: A video case study. Proceedings of the Fifth International Conference on the Foundations of Digital Games (pp. 9-16). ACM.

Bidarra, R., Boers, J., Dobbe, J., \& Huijser, R. (2008). Bringing a pioneer games project to the next level. Proceedings of the 3rd international conference on Game Development in Computer Science Education - GDCSE '08 (pp. 11-15). New York, New York, USA: ACM Press. doi:10.1145/1463673.1463676

Brand, J. (2011) DA12: Digital Australia. Retrieved from http://www.igea.net/wpcontent/uploads/2011/10/DA12FinalLinkVideo.pdf

Brown, Q., Lee, F., \& Alejandre, S. (2009). Emphasizing soft skills and team development in an educational digital game design course. Proceedings of the 4th international Conference on Foundations of Digital Games (pp. 240-247). ACM.

Charlier, N., \& De Fraine, B. (2012). Game-based learning in teacher education: A strategy to integrate digital games into secondary schools. International Journal of Game-Based Learning (IJGBL), 2(2), 1-12. doi:10.4018/ijgbl.2012040101

Cheng, K. S. (2009). Using game making pedagogy to facilitate student learning of interactive multimedia. Australasian Journal of Educational Technology, 25(1), 80-100.

Eagle, M., \& Barnes, T. (2009). Evaluation of a game-based lab assignment. Proceedings of the 4th International Conference on Foundations of Digital Games - FDG '09, 64. doi: $10.1145 / 1536513.1536533$

Haukka, S., \& Chorazy, E. (2011). Working in Australia's digital games industry. Innovation, (May), 108.

Hull, J. (2011, September). Solar accretion. PC Powerplay, pp. 38-41.

Hullett, K., \& Whitehead, J. (2010). Design patterns in FPS levels. Proceedings of the Fifth International Conference on the Foundations of Digital Games - FDG '10 (pp. 78-85). New York, New York, USA: ACM Press. doi:10.1145/1822348.1822359 
Linhoff, J., \& Settle, A. (2009). Motivating and evaluating game development capstone projects. Proceedings of the 4th International Conference on Foundations of Digital Games (Vol. 7, pp. 121-128). ACM.

Maxim, B. (2006). Work in progress: Use of Interdisciplinary teams in game development classes. Proceedings. Frontiers in Education. 36th Annual Conference, 25-26. doi:10.1109/FIE.2006.322615

Norton, L. (2009). Action research in teaching and learning. Abingdon, UK: Routledge.

Razak, A. A., Connolly, T., \& Hainey, T. (2012). Teachers' views on the approach of digital games-based learning within the curriculum for excellence. International Journal of GameBased Learning (IJGBL), 2(1), 33-51. doi:10.4018/ijgbl.2012010103

Rouse, R. (2004). Game design: Theory \& practice. Plano, TX: Wordware Publishing.

Schaefer, S., \& Warren, J. (2004). Teaching computer game design and construction. ComputerAided Design, 36(14), 1501-1510. doi:10.1016/j.cad.2003.10.006

Settle, A., Linhoff, J., \& Berthiaume, A. (2008). A hybrid approach to projects in gaming courses. Proceedings of the 3rd international conference on Game development in computer science education - GDCSE '08, 36-40. doi:10.1145/1463673.1463681

Copyright (C) 2013 Penelope Sweetser 